\title{
Innovation in the Teaching of Mathematics for Engineers through Modeling and Technology: a Mexican Experience
}

\section{Dr. Ruth Rodriguez Gallegos, Tecnológico de Monterrey}

Ruth Rodríguez is an Assistant Professor in the Mathematics Department at the Tecnológico de Monterrey, Monterrey Campus since 2007. She is a Math Education Researcher and Member of the National Researcher System and of the Mexican Committee of Educational Researchers. She was the Secretary of the Executive Committee and Member of the Network of Centers for Research in Mathematics Education (2009-2013). Since 2009, she has coordinated the faculty academy of differential equations in the Mathematics Department (ITESM Campus Monterrey). She is a thesis advisor and professor in the graduate programs of Education and Educational Technology and in the PhD program in Education at ITESM's Virtual University School of Education. Her interests are the teaching and learning of mathematics for future engineers through modeling and technological applications and the construction of a bridge between the discipline of mathematics education and the community of engineering education. 


\section{Innovation in the Teaching of Mathematics for Engineers Through Modeling and Technology: a Mexican Experience}

\section{Introduction}

The purpose of this paper is to share the experience of an educational practice in a private university in the Northeast of México (Tecnológico de Monterrey, Monterrey Campus). This experience is about a different way to teach Calculus and Differential Equations courses for future engineers based on a proposal developed by the Math faculty over 14 years. We start this document by showing the background of a proposed DE course.

\section{1) Background: Curricular Redesign of Mathematics for Engineers}

This proposal set off from the idea of re-designing the scholar mathematical discourse present in the Integral and Differential Calculus courses for engineers. It emphasizes that Mathematics is, above all, a human activity that answers several problems of different nature (physical, chemical, biological, etc.), and throughout this problem solving activity it is likely that the emergence of mathematical concepts, notions and procedures occurs.

The teaching of mathematics is an important goal to prepare critical citizens. These should develop the right skills to identify and solve problems in whatever context they encounter them as well as to express, test, revise or reject even their ways of thinking ${ }^{1,2,3,4}$. To achieve this goal requires the development of activities that allow students to recognize the importance of mathematics in everyday life situations.

In our Institution, the course of DE is the last formal course in basic math and the culmination of a series of courses on differential and integral calculus. It is intended that the student is able to use this knowledge in later subjects of his specialty which in fact does not happen automatically or successfully. This course is currently taught in 25 different engineering programs. According to each undergraduate study plan, it is found in the third or fourth semester.

Since in the current context it is important to prepare future engineers who are able to solve problems in their areas ${ }^{5}$, important background to this study is the redesign of the mathematics curriculum that the Engineering school started in our department in $1999^{6,7}$ The questions posed back then were not only how to teach mathematics -in terms of methodologies and didactic techniques- but also what and why to teach such content.

This proposal set off from the idea of re-designing the scholar mathematical discourse present in the Integral and Differential Calculus courses for engineers. It emphasizes that Mathematics is, above all, a human activity that answers several problems of different nature (physical, chemical, biological, etc.), and throughout this problem solving activity it is likely that the emergence of mathematical concepts, notions and procedures occurs. Students first learn the instrumental aspect of mathematical notions. After proper manipulation, they can theorize about the properties of the objects. This proposal considers that the emergence of mathematical knowledge is significant from the historical and epistemological points of view, and that the teaching of mathematics to future engineers should take into account these stages.

The outcomes of this proposal have been published in the form of four student textbooks -PreCalculus, Differential Calculus, Integral Calculus and Multivariable Calculus. 
It is in this spirit that our proposal takes over the walked path and enriches it with a proposal for the Differential Equations (DE) course: a mathematical modeling approach (see section 2); thus, emphasizing the fact that mathematical objects seen (the DE in our case) are primarily tools to model various phenomena in different contexts (physical, chemical, biological, social, etc.). To do this, we build on the Rodríguez' work ${ }^{8,9,10}$ which justifies the fact of choosing $\mathrm{DE}$ as an ideal tool to model phenomena of different nature. Students should find meaning within the mathematical object itself. The concept of mathematical modeling process is explained in the following section. The work is still in progress; however, there has been great advance in the curriculum design for Differential Equations.

\section{2) Designing a new proposal: the case of the Differential Equations Course}

Since August 2008, we have worked on the design and implementation of an innovative course of differential equations (DE). We want to demonstrate how DE can be taught to future engineers from the perspective of mathematical modeling and with the use of specific technologies.

This paper has been organized as follows. Section 2 is concerned with the difficulties in the teaching and learning of DE (2.1); the work of a departmental redesign for a Differential Equations course (2.2), and a theoretical perspective on mathematical modeling (2.3). Section 3 introduces a description of technologies used in the course (3.1); the characteristics of different learning environments (3.2), and the design and implementation of activities (3.3). Finally, section 4 discusses some valuable aspects related to theoretical modeling in engineering education, the importance of students' active and collaborative work and the use of technology. All section 4 is an essential part in the classroom activity as a means to model, experiment and rethink differential equations as tools to solve certain problems specific to various engineering specialties.

\section{1) Problems in the teaching and learning of $D E$}

In universities worldwide and specifically in Mexican universities, the teaching of differential equations predominantly focuses on analytical methods ${ }^{11}$ rather than on qualitative and numerical methods. This has been reported in spite of the wealth of both approaches in the teaching of $\mathrm{DE}^{12,13,14}$. This and other developments have been evidenced in the community of mathematics education for over 20 years, ${ }^{15,16,17,18,19,20}$ yet little changes have been reported in the daily classroom activities. While successful innovative proposals have been documented on teaching DE (especially internationally) over the past few years ${ }^{21,22,23,24,25}$ and some other research on the subject ${ }^{26}$ has been published, only few changes can be observed in classrooms and academic programs at various universities nationwide, particularly in the area of engineering. This proposal aims to acknowledge the importance of the changes in registers (algebraic, numeric and graphic), the modelling approach, and the effective use of technology in the teaching/learning process of DEs. 


\section{2) Re-designing a DE course, a collegiate experience}

Briefly discussed, the background of this departmental educational project ${ }^{27}$ started in August 2008 in our Institution. The main purpose was to re-design the DE course, implemented in our institution. It was a collegiate work of the faculty members of the Academy of Differentail Equations.

The early findings demonstrated that there were several educational proposals claiming the urgent need to reformulate the way DE was taught. They also emphasized the DE object as a tool to model various phenomena. ${ }^{21,23,28}$ We also observed a varied use of technology such as Open Educational Ressources (OER) and specialized software such as Mathematica and Maple to teach certain topics in DE. As a result and with the active participation of the faculty members of this group, a new syllabus for the DE course at the undergraduate level was approved systemwide (32 campi). Below is presented the contents (sections) of the syllabus.

*Algebraic methods: ODE first and second order; Laplace Transform, DE Linear Systems. Partial DE (PDE): heat, wave and Laplace.

*Numeric methods: Euler method.

*Qualitative methods: Slope field

\section{3) A Mathematical Modeling perspective in the DE course from the Community of Mathematics Education}

The study of mathematical modeling began thirty five years ago. It aimed to bridge school mathematics and the mathematics used in other settings. From six perspectives identified for mathematical modeling ${ }^{29}$, this paper focuses on the realistic or applied. This perspective stresses the importance of teaching through mathematical modeling as a more pragmatic approach to solve real problems and to develop certain competencies in students, particularly those of modeling (see 2.4).

First, the basic background to support our vision of mathematical modeling in school is based 30,31 on those who first postulated modeling as just the relationship between mathematics and "reality".

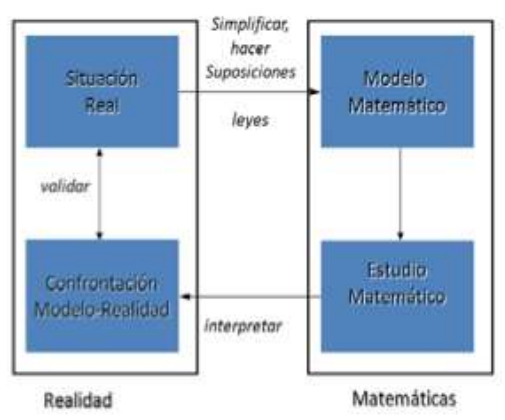

Figure 1: Modelling Description
Moreover, several other authors further divide $^{32}$ this first sense of modeling stages and emphasize the importance of the transitions between stages. Also, unlike the Anglosaxon "real model" study, the term "pseudo-concrete model" ${ }^{132}$ is coined to basically refer to the intermediate stage between reality or actual situation and the mathematical model. 
Finally and after a detailed study of several authors who proposed to visualize mathematical modeling from the school scope, the authors chose to further this study adopting the description of this process in terms of stages and transitions between stages (eg. A-> B) as shown in the following figure ${ }^{8,9,10,33}$ :

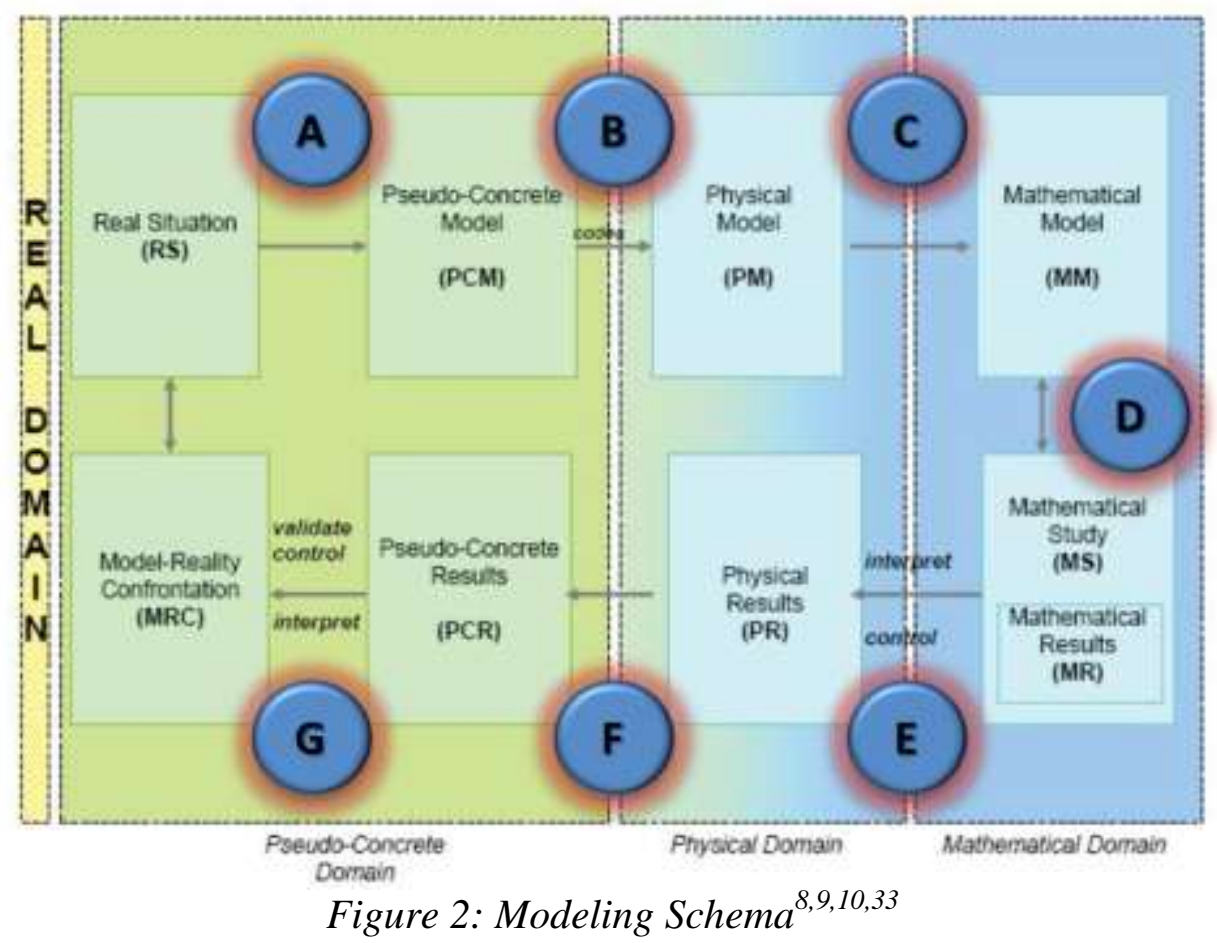

This proposal explicitly incorporates two important elements: the inclusion of a physical domain which is modeled (probably an extra-mathematical, biological, or chemical domain) and the importance given to the pseudo-concrete domain ${ }^{32}$ as the difficult transition for students but key in the modeling process (real model). It is important to note that the mathematical model is understood as the different graphical representations of the ED: solution graph, the DE itself as an analytical model, and a table of data that can eventually be modeled by a DE and / or its solution.

The literature analysis has made it clear that mathematical modeling has allowed multiple benefits when used with students at different educational levels. The benefits have translated into the achievement of connections between school mathematics and everyday life mathematics, reduction of anxiety towards the subject, promotion of communication and collaborative work, and the development of math skills. ${ }^{34,35,36,37}$

In more recent studies, a precise theoretical approach ${ }^{38,39,40}$ has been formulated to implement mathematical modeling in the classroom, which includes among others the role of technology in learning mathematics ${ }^{41,42,43,44}$, the importance of collaborative learning, ${ }^{42}$ and the development of modeling competencies ${ }^{45}$ according to the specific levels ${ }^{46}$ in the development of such competencies. 


\subsection{1) Development of modeling skills in a Differential Equations course}

Together with the above-mentioned, it is important to highlight that the interest in the development of skills has been a matter of concern for different national and international institutions such as the Tuning Latin American Project ${ }^{47}$, the Accreditation Board for Engineering and Technology ${ }^{48}$ and the 2015 Mission/Vision statements of Tecnológico de Monterrey $^{5 \mathrm{a}}$, all of which base their views on the development of proficient students to solve problems in their settings and acquire the technological and collaborative skills. Likewise, the Organization for Economic Cooperation and Development ${ }^{49}$ (OCDE) presents the development of mathematical competencies and more specifically those in modeling as important. In an effort to define these competences ${ }^{50,51}$ it is shown that mathematical modeling skills include the abilities to perform the modeling process adequately and to focus it properly. It is also concerned with the possibility of setting those skills into action. Based on the above approach, this study intends to present the design of activities that were designed to facilitate the transition between the various stages of mathematical modeling by having the students face situations that are related to the contexts that students commonly live in engineering.

\section{3) Methodology in the design and implementation of innovative material in the DE course}

Since 2008, innovative material (hands-on activities, laboratory practices, modeling and simulation practices, worksheets/spreadsheets) has been developed for the DE course. Its main axis is concerned with the modeling of biological, physical or chemical phenomena. Recent research has shown the need to change the way to teach DE, from the "traditional" way, which emphasizes analytical methods, to an integrative mode, which uses graphical and numerical methods. This integrative mode should enable students to identify and recognize a DE in its different representations; and thus, improve the learning of DEs as mathematical objects. The student should not only learn how to use techniques to solve DEs but also learn the application of the DE as a tool to model several problems. This is also strengthened through the use of specific technology and software such as CAS (Maple and Mathematica); simulations, and laboratory practices with sensors in the classroom to better model and understand the phenomenon to study: temperature, an RC circuit, or a spring-mass system. The student should be capable of integrating technical knowledge (DEs) with practical skills through modeling. Different learning active environments play an important role in promoting the implementation of the course with hands-on, modeling, and simulation activities; and the development of communication, problem solving and modeling skills.

\section{1) Using technology in a DE course}

Within the available software to teach mathematics, there are several educational technologic products meant as tools with no explicit disciplinary content. Students and teachers should incorporate modules that are meant to produce texts and charts; and store and organize information. The program offers a space for data input and sets of commands to perform certain actions on the entered data. Its use requires that teachers know the structure of the software and the commands that symbolize the various operations that can be performed, plan the activity to give meaning to the resource. Depending on the activity, it is necessary to build data files to implement them on the computer. Furthermore, their use requires students to understand the 
working model they offer and to handle the necessary commands to carry out the activity. On the other hand, the assorted technology available is considered as follows:

a) specific mathematical CAS software such as Maple ${ }^{51}$ and Mathematica ${ }^{52}$ CAS, or other resources freely available on the Internet as Wolfram Alpha ${ }^{53}$.

b) graphing calculators Symbolic Computation (CAS family example TI Texas Instruments Nspire CAS $\mathrm{CX}^{54}$ ) and

c) in addition to previous devices, the use of sensors ${ }^{54}$ (temperature, voltage, motion) so that the student can perform some experimental practices in the classroom and see the illustrated form of a DE model in a real phenomenon, taking real data and adjusting, suggesting a model and verifying. When it is not possible to take this to the classroom, we recommend the use of the open educational resources and DE Tools as described below.

d) Open Educational Resources (OER) as $\mathrm{PhET}^{56}$ simulators from the University of Colorado and the DE Tools ${ }^{57}$.

The technology described above enables the design of activities in which the modeling skills may be eventually developed and foster meaningful learning of DE as a mathematical object as well as a tool to model various phenomena.

\section{2) Description of three different models of learning environnments}

Since August 2011 the course has been taught in three varied learning environments, as follows:

a) "Standard" (Traditional) Hall. The room has infocus, a pc, a projector, and a white board in the front of the classroom.
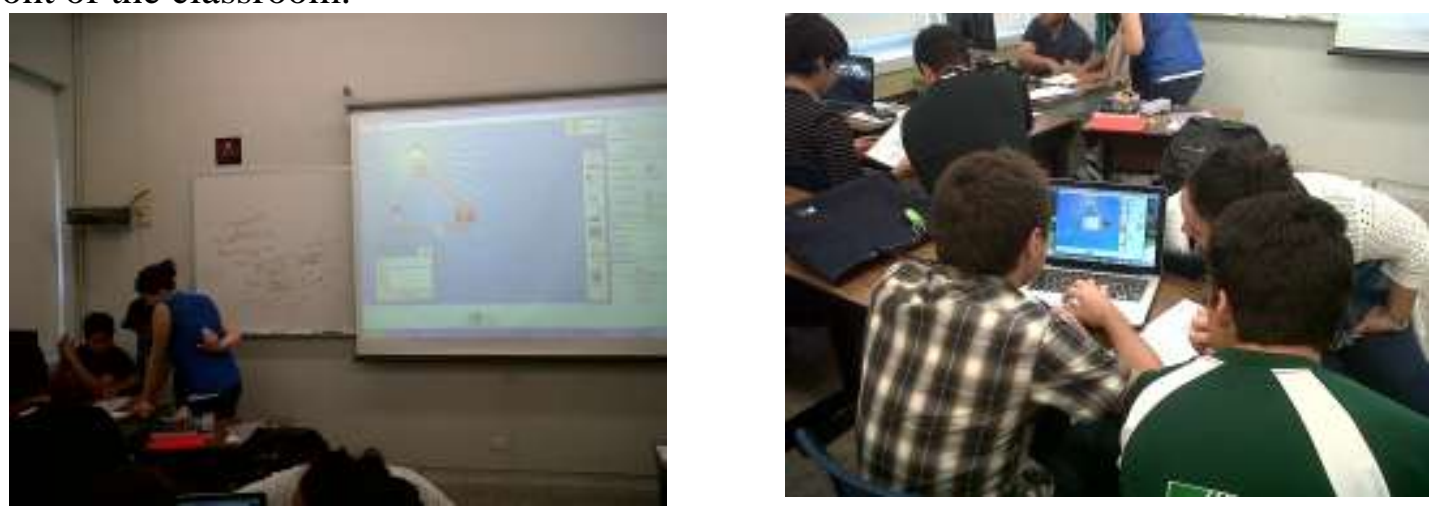

Figure 3: Images of classroom activity (traditional hall) on the topic of Electric Circuits through the PhET simulator

b) Intelligent Classroom (smart board in the front, 2 screens with side infocus and projector, many white boards and movable chairs to facilitate teamwork) . 

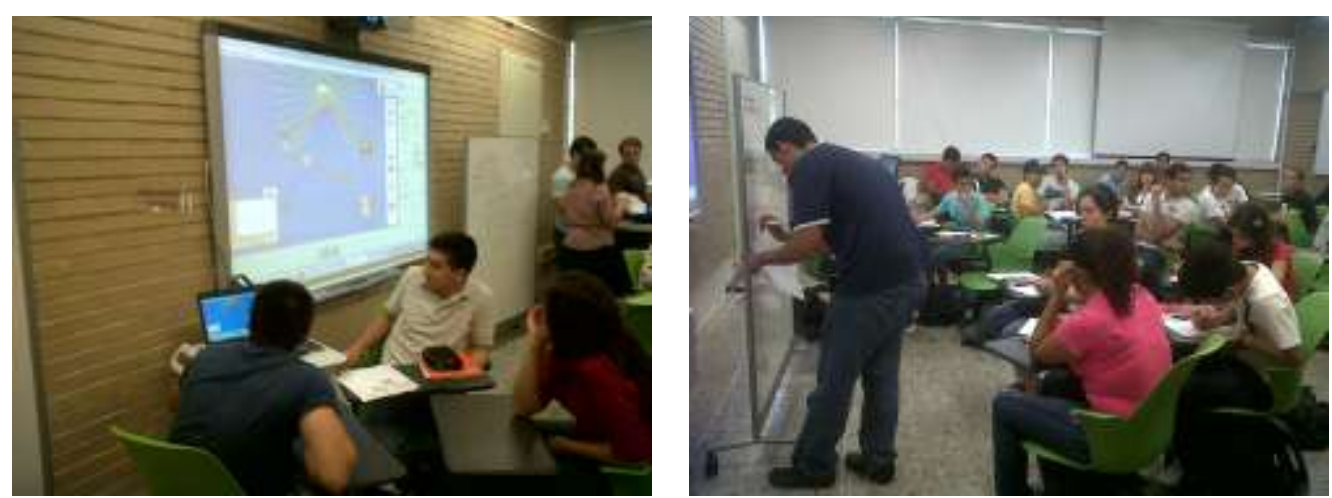

Figure 4: Images of classroom activity (Technological activity) on the topic of Electric Circuits through the PhET simulator

c) ACE Classroom (4 screens and side infocus projector, 4 large white boards, 8 fixed round tables for 3 three-student teams. This kind significantly promotes the team's active work throughout the course.
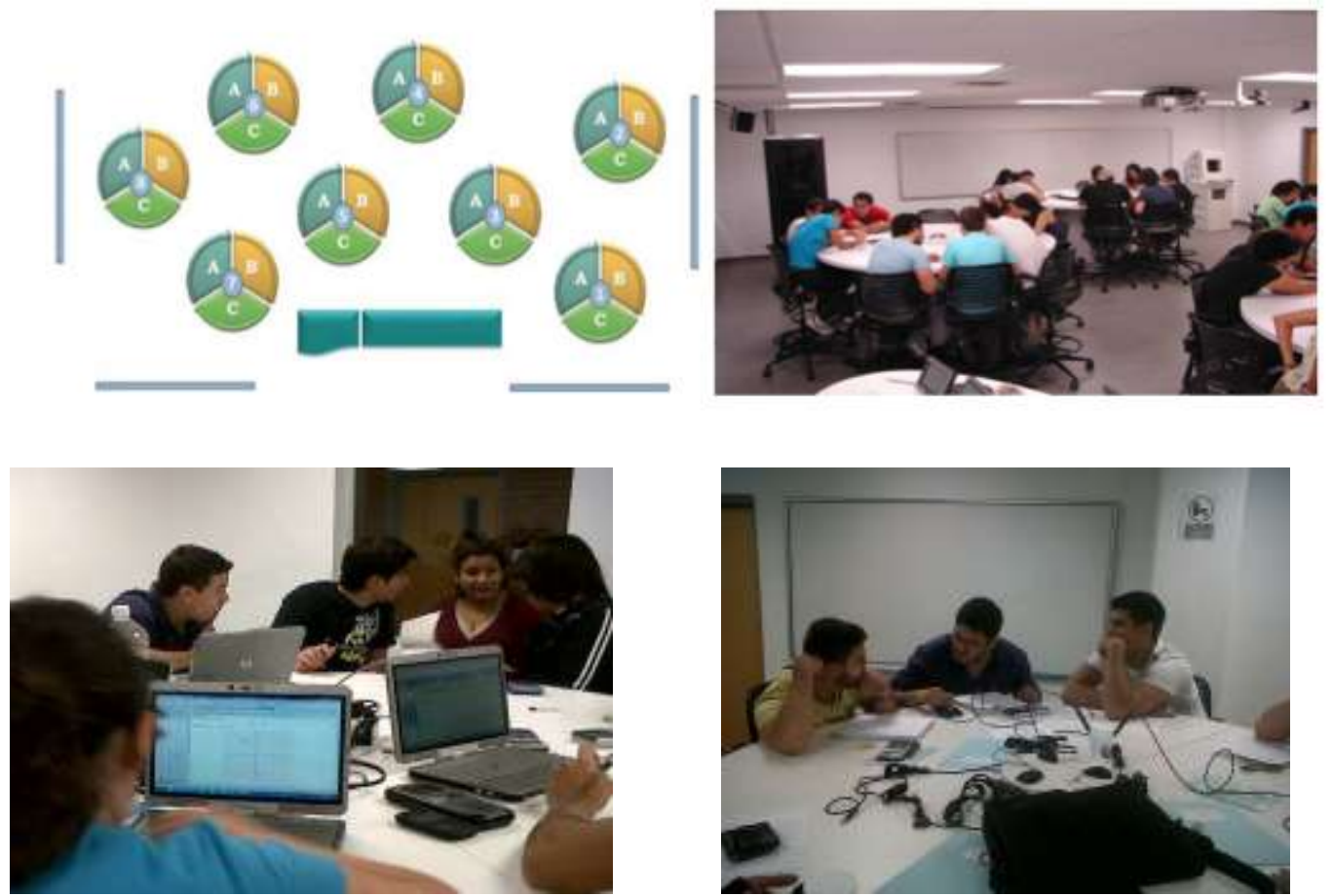

Figure 5: Images of classroom activity in ACE Room using Maple and sensors

Since 2010, we have implemented the DE course in this ACE classroom following the North Carolina University SCALE-UP model ${ }^{42}$. This last learning environment is called the ACE Room (Student Centered Learning, $\mathrm{ACE}^{41,43,44}$ ). It is designed for students to be highly collaborative and to foster active learning. In addition to the technology described, it also has a touch HP laptop per team equipped with Internet; the mathematical softwares Maple, Mathematica and MatLab already installed on it and the possibility to have visibility and control over the work on each laptop in the professor's mainframe via the Classroom Manager software. 


\section{3) Designing modelling activities}

Following are four activities designed to teach DE in two aspects: as models to represent various phenomena and as mathematical objects. In particular, we want to explore some of the modeling stages defined in Figure 2 (see transition between stages) with the idea that the student through these tasks and the use of appropriate technology develops his modelling skills through the DE object.

3.3.1) Modeling the temperature of hot water (Experimentation to give meaning to the DE model, empirical deduction of a model)

The change in temperature of an object: the situation is to measure how the temperature of liquid changes (boiling water, oil or alcohol) versus time, by using the temperature sensor EasyTemp. Students are asked to establish the "way in which temperature changes in regards to time by using graphical and numerical representations provided by the TI-Nspire CX CAS. In other words, through a real situation students can understand the underlying DE associated with the phenomenon.

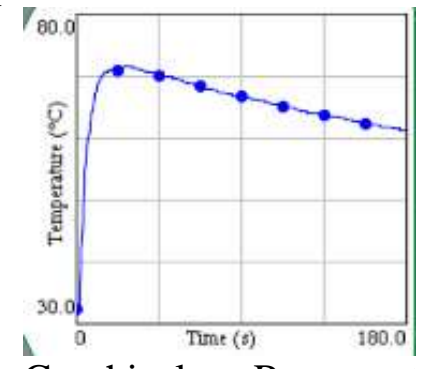

Graphical Representation (data provided by the sensor Easy Temp)

Transition $A \rightarrow B \rightarrow C$

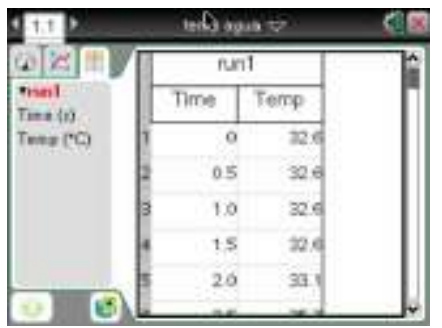

Numerical Representation (data provided by the sensor Easy Temp)

Transition modeling $A \rightarrow B \rightarrow C$
The DE is:

$$
\frac{d T(t)}{d t}=k\left(T(t)-T_{m}\right)
$$

(Newton law)

The general solution is:

$$
T(t)=T_{m}+C e^{k t}
$$

With the "dsolve" TI command or Wolfram Alpha AlgebraicRepresentation Transition Modeling $D$

Figure 6: Steps (and transitions between them) in the modeling cycle; different representations of the DE of temperature

3.3.2) Modeling the mixing of water and salt in a tank (simulation to recreate the situation for students to set the DE associated to the phenomenon)

Study how salinity changes in a tank of water: the situation is to measure the amount of salt in a tank in regards to time, using the Phet simulator. Students are asked to establish the "way in which the amount of salt in a tank of water changes in regards to time" by the initial use of an activity and the the simulator. In other words, through a real situation, students can propose a DE to model the phenomenon. 


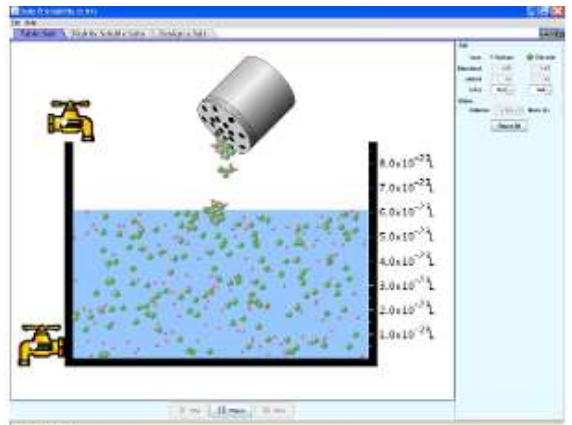

Example of the Physical (Virtual) Model with PhET

Transition modeling $A \rightarrow B \rightarrow C$
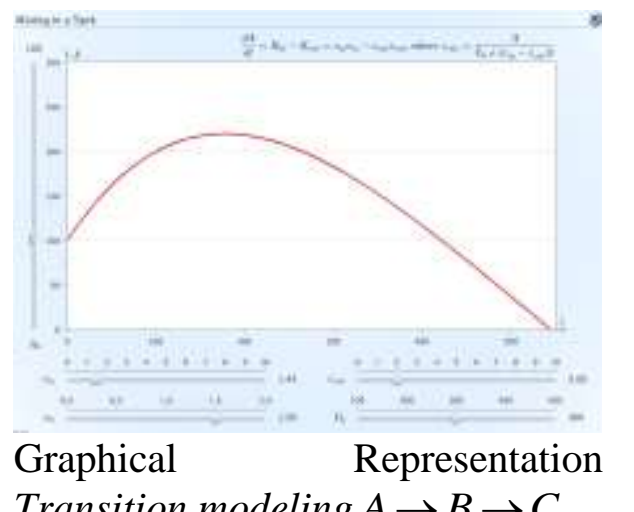

The DE is:

$\frac{d x}{d t}=C e * f e \quad \frac{x}{V(t)} \div * f_{s}$

With the "dsolve" command of the IT or Wolfram Alpha

Analytical

Representation

Transition modeling $D$

Figure 7: Steps (and transitions between them) in the modeling cycle; different representations of the DE of a tank (mixing context)

To implement the modeling activity of the mixing problem with differential equations the following steps are considered:

Stage 0 . Organization in teams of 3 students.

Stage 1. Creation of awareness to the phenomenon through a video showing the hypothesis to the problem

Stage 2. Three-part activity begins:

Part I: Identification of potential variables to study. It aims to highlight the step in the diagram modeling the "real" situation or pseudo-concrete (Text of the exercise) to a graph / qualitative representation of the evolution of the amount of interest.

Part II: Idenitification of the Mix Mathematical Model in its analytical representation (DE). Through the writing of the activity, the students are guided in the theoretical explanation of the tank model (chart-> DE). What is mainly discussed is the way in which the concentration changes over time according to the law of conservation of matter. In this step, based on the modeling diagram, the student goes from the Pseudo Concrete Model (statement) to the physical model (diagram tank) and / or the "virtual physical" model (simulator) to the mathematical model as a first order DE.

Afterwards, students are asked to analyze the type of DE (ordinary) and its order (first order); to solve it by previously identifying the method to use (linear model); and to finally sketch his graph. This last part corresponds to the part in the modeling process to establish a mathematical model in its analytical representation (DE) and / or graphic (curve of the solution function). It is important to note that this part of the DE resolution is an essential part of the course; however, this teaching proposal is only one part of the modeling process. This part will eventually be facilitated through a technological resource.

Step 3. Learning affirmation done in three ways:

1. Assigning for homework to solve some problematic mixing situations, in similar contexts and / or slightly different from those treated in class.

2. Giving a monthly exam (short term) or the final exam containing a mixing problem 
3.3.3) Modeling the change of charge in an RC circuit (experimentation and simulation to recreate the situation for students to become familiar with the electrical phenomenon and to verfy the DE associated to the phenomenon)

We are interested in the evolution of the charge $q(t)$ in a capacitor, $q(t)$ : the question is to measure how the charge $\mathrm{q}(\mathrm{t})$ changes in a capacitor $\mathrm{C}$ over time, using the voltage sensor. Students are asked to establish "the way in which the charge in Capacitor C changes over time t" by using graphical and numerical representation using the calculator TI-Nspire CX CAS. In other words, through a real situation, students can understand the underlying ED.

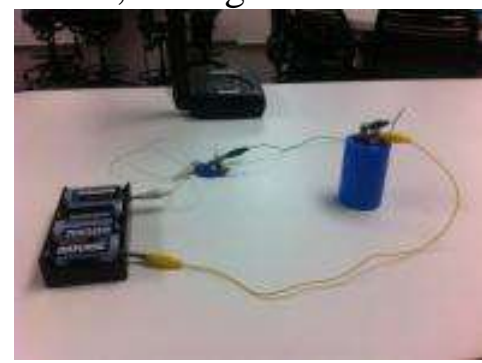

Example of the Physical Model (RC Circuit) Modeling Transition $A \rightarrow B$

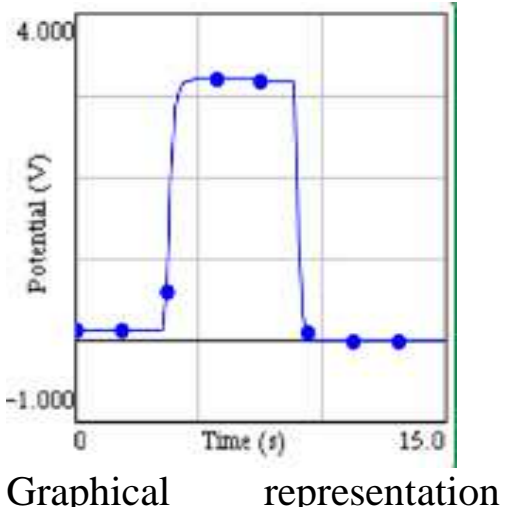

provided by the voltage sensor Easy Link

Transition $A \rightarrow B \rightarrow C$

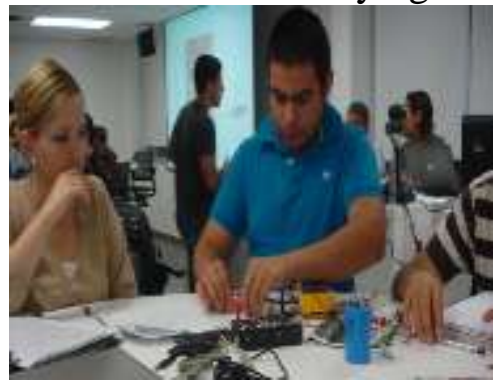

Lab practice in a DE course about the RC Circuit

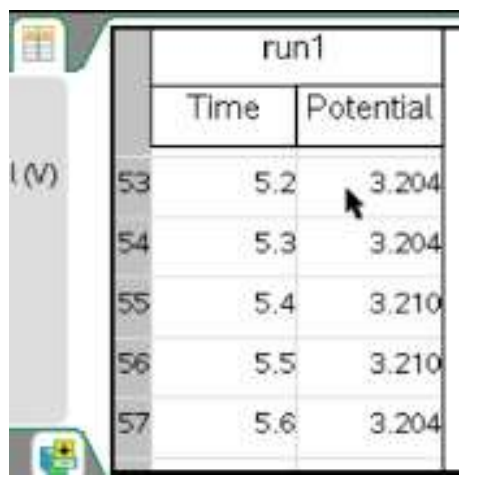

Numerical Representation, data provided by the sensor voltage + Easy Link) Modeling

The DE is: $R \frac{d q(t)}{d t}+\frac{1}{C} q(t)=E_{0}$ (Kirchoff's law) The general solution to the DE is:

$$
q(t)=\frac{E_{0}}{R}-\frac{E_{0}}{R} e^{\frac{-t}{R C}}
$$

\section{"Dsolve" TI command Analytic Representation Transition Modeling} $A \rightarrow B \rightarrow C$

Figure 8: Steps (and transitions between them) in the modeling cycle; different representations of the DE in the setting of an RC Circuit (charge and discharge of a capacitor)

Then students are asked to model an RL circuit, but due to the lack of material in the laboratory (in particular, coil L), the PhET simulation is used to accomplish this assignment. It is a good moment to introduce a variable, a voltage source with an AC (sinusoidal). Therefore, the way to solve it is analyzed in terms of steady and transient state. 

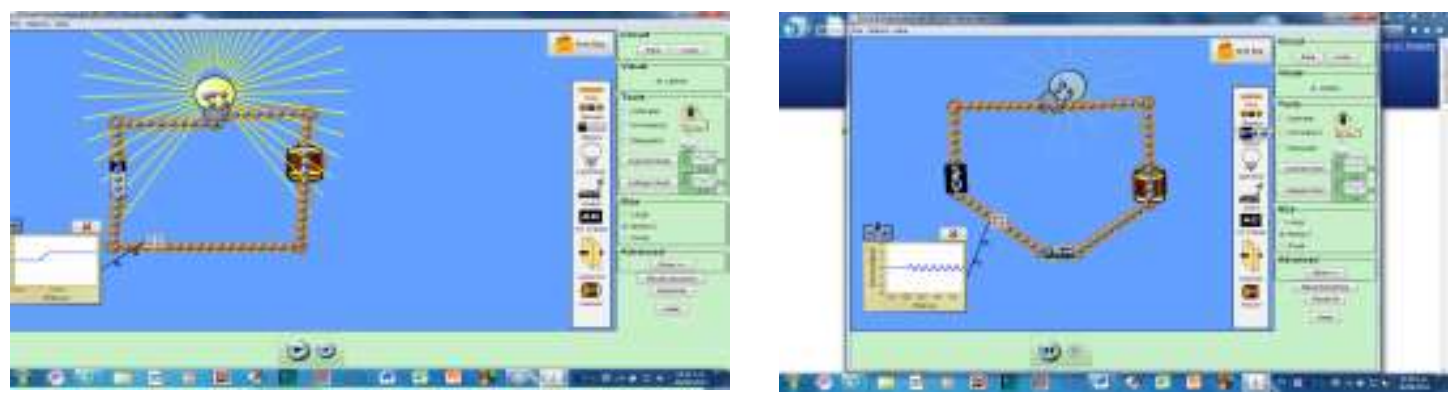

Figure 9: Examples of students' productions at the time of modeling the current in an RL circuit with the PhET simulator, using alternating current (variable) in an RL circuit

In general, the implementation of this class activity was designed as follows: Stage 1: Discuss in groups the previous knowledge regarding the DE analytical model that models the change of the load of a capacitor in an RC circuit. Step 2: Assemble an electrical RC circuit and measure the load capacitor through a voltage sensor. The material used for the activity consisted of a circuit (a bulb, a capacitor, a set of four batteries and connectors) for each computer, a TI sensor of voltage, a TI browser and the protocol to the practice. Step 3: Analyze the graph generated by the sensor and recognize of its shape; analyze the behavior in regards to the modeled real phenomenon. Step 4: Solve analytically the DE of an RC circuit with constant voltage input with the linear DE method previously studied in class by 3-member teams. Step 5: Solve a DE of an RC circuit of variable voltage input analytically and individaully.

3.3.4) Modeling a spring-mass system (experimentation and simulation to recreate the situation, familiarize students with the mechanical phenomenon, and verify the DE associated to the phenomenon)

Similar to the other two aforementioned settings (temperature and electrical circuits) the modeling of a mass-spring mechanical system can be worked in class thanks to the technology of the TI Nspire CX CAS and the CBR motion sensor. In this mechanical context, students can provide a context for the data and illustrate once again the meaning of mass $\mathrm{m}$ parameters, environmental resistance and spring constant $\mathrm{k}$ in the mathematical model (second-order).

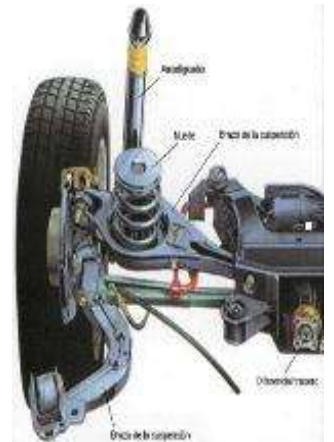

The "Real

Situation":

explains the

operation of a car

buffer.

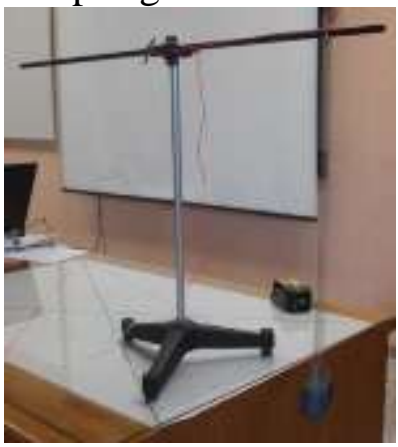

Physical Model: massspring system Transition modeling stages $A \rightarrow B$

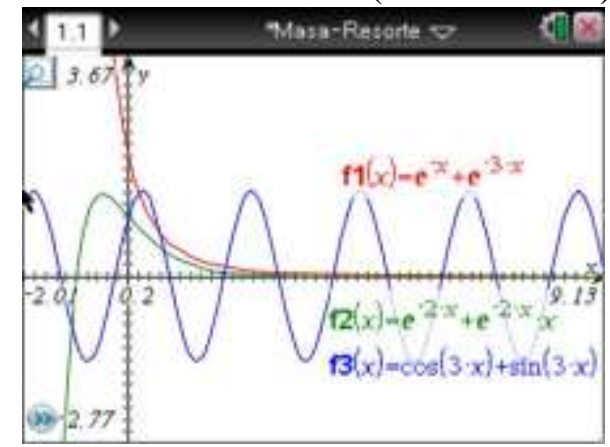

Mathematical models: graphs of the solutions of the DE

Transition modeling stages $A \rightarrow B$

$D \rightarrow E \rightarrow F \rightarrow G \rightarrow H$

Figure 10: Steps and transitions between them modeling cycle; different DE representations of the model in play for the position of a mass attached to a spring 
With this, students can also exemplify the three possible cases (see figure 10 of the DE method with constant, homogeneous coefficients and better understand the proposed assumptions of the particular solution by the method of undetermined coefficients for DE with constant, nonhomogeneous coefficients. In this particular case, we also take good advantage of the DE interface simulator Tools on handling parameters to better understand the DE regarding the possible values of the course mass $\mathrm{m}$, the spring constant $\mathrm{k}$, and the resistance of the beta medium.
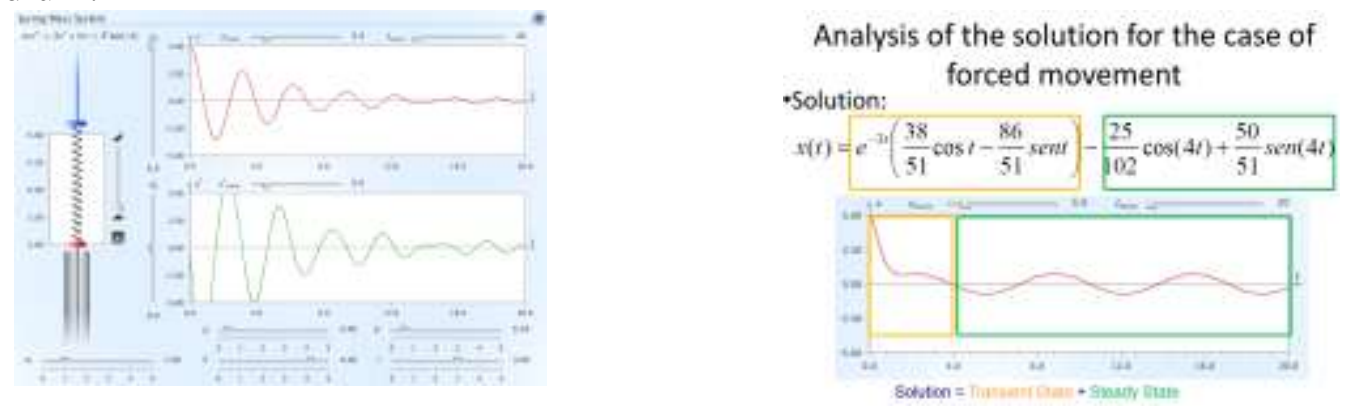

Figure 11: Studying a mass-spring through DE simulator Tools and qualitative study of the solution in terms of steady and transient state
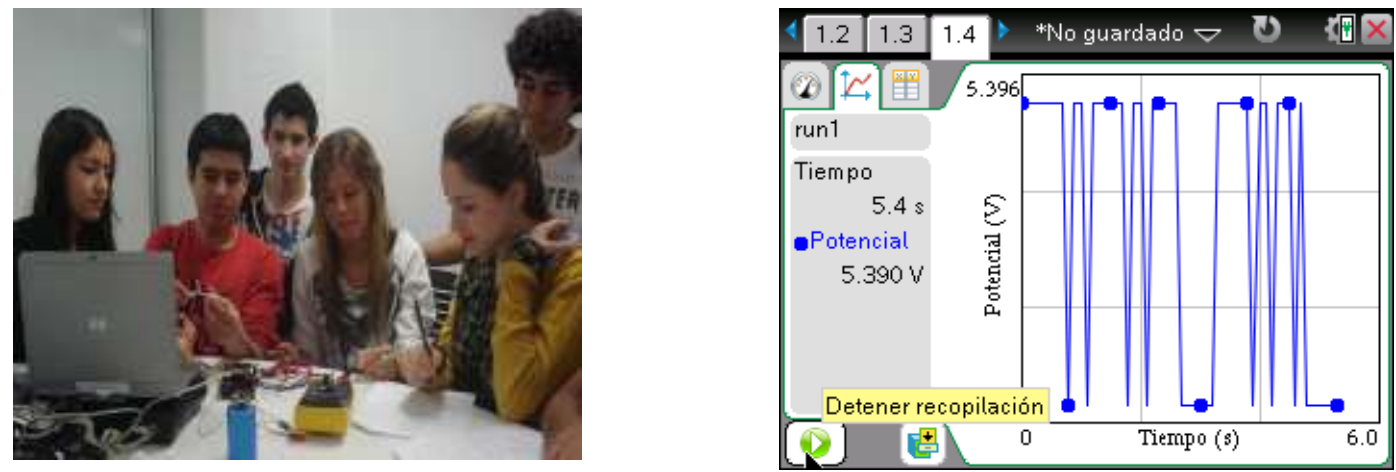

Figure 12: Steps and transitions between them modeling cycle; representations of different DE of the model used for electrical circuits

\section{Conclusion}

This paper aimed at presenting the activity design in the DE course, particularly showing the theoretical foundations that support the design and eventual implementation of activities in the classroom. Without hesitation, the role of the student-centered learning environments such as the ACE classroom and the Technological classroom as well as the proper use of appropriate technology used in this study (calculator, sensors, software, simulators) should be discussed indepth in a later study.

It is important to highlight the role that technology plays in a Differential Equations course geared at future engineers. The emphasis given to DE as models to represent different phenomena in nature, and further emphasis on showing the students' modeling stages (where the object DE is one of many ways to represent a phenomenon) show a large potential to use technology in the classroom not only to simplify the algorithmic part but also to solve through dsolve; see graphic solutions, see behaviors in data tables, analyze the meaning of parameters in the solution graphs and above all show the experiment and data collection prior to the 
establishment of a DE. Given the portability of current technological devices (e.g. calculator and sensors) partners can take them to a classroom provided it has the infrastructure and minimum equipment necessary to implement this in class. The idea is not to teach another discipline in a math class, but to encourage future engineer to give context to DE seen in the first-or secondorder and to re-signify the parameters, variables or behaviors seen in experiments in the proposed model. Finally, it aims to highlight the richness of the new course as to show students the range of possible multiple representations of the same mathematical object (DE). It is expected that at the end of this course, the future engineer will have a better idea of the meaning of DE in both models to represent various phenomena and solutions to be the same over a catalog of analytical methods in solving DE. It is important to note the vast access to simulators with which students relate real phenomena and key concepts of DE. Finally, we conclude this paper by emphasizing the importance of the teaching of mathematics in general and DE through modeling, especially the work of designing activities based on the stages of the process and the contribution of each to lead students to move between key stages and modeling. This study reveals the importance of identifying the various skills a student must develop for modeling competences. Evidence has shown that future engineers achieve better understanding of the math concepts after living this educational practice and further develop other skills (social, communicative, modeling and technological) along with the mathematical.

\section{Bibliography}

1. Alsina, C. (2007). Teaching applications and modelling at tertiary level. Modelling and Applications in Mathematics Education, The 14th ICMI Study, 10(44), 469-474. doi:10.1007/97803872982212

2. Confrey, J. (2007). Epistemology and modelling-overview. Modelling and Applications in Mathematics Education, The 14th ICMI Study, 10(3), 125-128. doi:10.1007/97803872982214

3. Lesh, R., \& Yoon, C. (2007). What is the distinctive in (our views about) models and modelling perspectives on mathematics problem solving, learning, and teaching? Modelling and Applications in Mathematics Education, The 14th ICMI Study, 10(31), 161-170. doi:10.1007/978038729822115

4. Muller, E., \& Buskhardt, H. (2007). Applications and modelling for mathematics-overview. Modelling and Applications in Mathematics Education, The 14th ICMI Study, 10(34), $267-274$. doi:10.1007/978038729822128

5. Tecnológico de Monterrey. (2005). Visión Misión 2015. Documentos del Sistema Tecnológico de Monterrey. Recuperado de http://www.itesm.mx/2015/recursos/2015-Vision-Mision.pdf

6. Salinas, P. y Alanís, J.A. (2009). Hacia un paradigma en la enseñanza del cálculo dentro de una institución educativa. Revista Latinoamericana de Matemática Educativa (RELIME, 2010). 12 (3): 355-382. México. Disponible en: http://www.clame.org.mx/relime.htm

7. Salinas, P. Alanís, J.A. y Pulido, R. (2011). Cálculo de una variable. Reconstrucción para su enseñanza y aprendizaje. DIDAC, 56-57. Universidad Iberoamericana: México.

8. Rodríguez, R. (2007). Les équations différentielles comme outil de modélisation en Classe de Physique et des Mathématiques au lycée : une étude de manuels et de processus de modélisation en Terminale S. Tesis doctoral. Escuela Doctoral de Matemáticas, Ciencias y Tecnologías de la Información. Universidad Joseph Fourier, Grenoble, Francia. Recuperado el 6 de febrero de 2011 de: http://tel.archivesouvertes.fr/docs/00/29/22/86/PDF/TheseRuthRdz.pdf.

9. Rodríguez, R. (2009). Differential Equations as a tool for mathematical modelling in Physics and Mathematics courses. A study of textbooks and modelling processes of high-school senior students. En Mathematical applications and modelling in the teaching and learning of mathematics. Proceeding from Topic Study Group 21 at ICME-11 en Monterrey, Mexico.Universidad de Roskilde. Dinamarca. 2009.

10. Rodríguez, R. (2010). Aprendizaje y Enseñanza de la Modelación: el caso de las ecuaciones diferenciales. Revista Latinoamericana de Matemática Educativa, 13 (4-I): 191-210. México. Disponible en: http://www.clame.org.mx/relime.htm 
11. Arslan, S., Chaachoua, H. y Laborde, C. (2004). Reflections on the teaching of differential equations. What effects of the teaching of algebraic dominance? Memorias del X Congreso Internacional de Matemática Educativa (ICME XI). Dinamarca.

12. Artigue M. (1996). Teaching and learning Elementary Analysis. Memorias del VIII Congreso Internacional de Matemática Educativa (ICME VII), Selected Lectures, 15-29. Sevilla, España.

13. Arslan S. y Laborde C. (2003). Un outil favorisant le jeu de cadres : Cabri. Une étude de cas dans l'apprentissage des Equations Différentielles. Memorias del Congreso Europeo (Actes du Congrès Européen, ITEM). Reims, Francia.

14. Moreno J. y Laborde C. (2003). Articulation entre cadres et registres de représentation des équations différentielles dans un environnement de géométrie dynamique. Memorias del Congreso Europeo (Actes du Congrès Européen, ITEM). Reims, Francia.

15. Artigue M. (1989). Une recherche d'ingénierie didactique sur l'enseignement des équations différentielles du premier cycle universitaire. Cahier du séminaire de Didactique des Maths et de l'Informatique de Grenoble, édition IMAG, 183-209. Grenoble, Francia.

16. Artigue, M. (1992). Functions from an Algebraic and Graphic Point of View: Cognitive Difficulties and Teaching Practices, en Dubinsky, E. \& Harel, G (eds), The concept of function: Aspects of epistemology and pedagogy, MAA notes 25. Washington, DC: MAA.

17. Artigue, M.(1995). La enseñanza de los principios del cálculo: problemas epistemológicos, cognitivos y didácticos, en Gómez, P.(ed.), Ingeniería didáctica en educación matemática. Grupo Editorial Iberoamérica. México.

18. Blanchard, P. (1994) Teaching differential equations with a dynamical systems viewpoint, en The College Mathematics Journal, 25, 385-393.

19. Kallaher, M. (1999). Revolutions in Differential Equations, exploring ODES with modern technology, en MAA Notes 50, Washington, D.C: MAA.

20. Rasmussen, C. y Whitehead, K. (2003). Learning and Teaching Ordinary Differential Equations. The Mathematical Association of America. MAA. Disponible en: http://www.maa.org/t and 1/sampler/rs $7 . \mathrm{html}$

21. Lomen, D. y Lovelock, D. (2000). Ecuaciones Diferenciales a través de gráficas, modelos y datos. México: CECSA.

22. Barnes, M. y Fulford, G. (2002). Mathematical Models with Case Studies. A differential Equation Approach Using Maple. Taylor \& Francis Inc.: New York.

23. Blanchard, P., Devaney, R. y Hall, G. (2006). Differential Equations. (3a edición). Belmont: Cengage.

24. Boyce, W. y DiPrima, R. (2010). Ecuaciones Diferenciales y problemas en valores de la frontera. Limusa Wiley, $5^{\text {a }}$ edición, México.

25. Brannan, J. y Boyce, W. (2007). Ecuaciones Diferenciales. Una introducción a los métodos modernos y sus aplicaciones. Primera edición. Grupo Editorial Patria: México.

26. Rasmussen, C. (2001). New directions in differential equations: A framework for interpreting students' understandings and difficulties. The Journal of Mathematical Behavior, (20, 1): 55-87.

27. Rodríguez, R. (2010). Diseñando un curso de Ecuaciones Diferenciales a través del Trabajo Colegiado: una experiencia docente. Memoria de la XIII Escuela de Invierno en Matemática Educativa. Red CIMATES: Monterrey.

28. Zill, D. (2009). Ecuaciones diferenciales con aplicaciones de modelado. (9a. Edición). México: Cengage.

29. Kaiser, G., \& Sriraman, B. (2006). A global survey of international perspectives on modelling in mathematics education. Zdm, 38(3), 302-310. doi:10.1007/BF02652813

30. Blum, W. y Niss, M. (1991). Applied mathematical problem solving, modeling, applications, and links to other subjects - State, trends and issues in mathematics instruction. Educational Studies in Mathematics, 22 (1), 37-68.

31. Niss, M., Blum, W. y Galbraith P. (2007). Introduction. ICMI Study 14: Applications and Modelling in Mathematics Education. New York: Springer, 3-32.

32. Henry, M. (2001). Notion de modèle et modélisation dans l'enseignement. En Henry, M. (Ed.), Autour de la modélisation en probabilités (149-159). Besançon : Commission Inter-IREM Statistique et Probabilités.

33. Rodríguez, R. (2012). Modelación y uso de tecnología TI Nspire CX CAS en la enseñanza de las ecuaciones diferenciales. Revista Innovaciones Educativas de la Texas Instruments, Duodécima Edición, pp. 24-26. México. Disponible en: http://education.ti.com/sites/LATINOAMERICA/downloads/pdf/Revista_innovaciones_2012_web.pdf

34. Aravena, M. D., \& Caamaño, C. E. (2009). Mathematical models in the secondary Chilean education. In M. 
35. Bonotto, C. (2007). How to replace word problems with activities of realistic mathematical modelling. Modelling and Applications in Mathematics Education, The 14th ICMI Study, 10(32), 185-192. doi:10.1007/978-0-387-29822-1_18

36. Lombardo, D. H., \& Jacobini, O. R. (2009). Mathematical modelling: From classroom to the real world. In M. Blomhoj \& S. Carreiro (Eds.), Mathematical applications and modelling in the teaching and learning of mathematics ( $1^{\circ}$ ed., pp. 35-46). Dinamarca: Roskilde University.

37. Von Hofe, R., Jordan, A., Hafner, T., Stolting, Pa., Blum, W., \& Pekrun, R. (2009). On the development of mathematical modelling competencies-The PALMA longitudinal study. In M. Blomhoj \& S. Carreira (Eds.), Mathematical applications and modelling in the teaching and learning of mathematics (pp. 47-60). Dinamarca: Roskilde University. doi:10.1093/teamat/22.3.123

38. Rodríguez, R. (2012). Modelación y uso de tecnología TI Nspire CX CAS en la enseñanza de las ecuaciones diferenciales. Revista Innovaciones Educativas de la Texas Instruments, Duodécima Edición, pp. 24-26. México.

39. Rodríguez, R., Quiroz, S. e Illanes, L. (2012). Competencias de modelación y uso de tecnología en Ecuaciones Diferenciales. XXVI Reunión Latinoamericana de Matemática Educativa (RELME XXVI). CLAME: Belo Horizonte, Brasil.

40. Rodríguez, R. y Quiroz, S. (2012). Modelación y Tecnología en Ecuaciones Diferenciales. Memorias del VI Seminario Nacional de Tecnología Computacional en la Enseñanza y el Aprendizaje de las Matemáticas. Asociación Mexicana de Investigadores del Uso de la Tecnología en Educación Matemática A.C. México.

41. Alvarado, C., Domínguez, A., Rodríguez, R. y Zavala, G. (2011). Expectancy Violation in Physics and Mathematics Classes in a Student-Centered Classroom. American Institute of Physics Conference Proceedings. Estados Unidos ISSN : 15517616

42. Beichner, R., Saul, J., Abbott, D., Morse, J., Deardorff, D., Allain, R., Bonham, S., Dancy, M., \& Risley, J. (2007). The Student-Centered Activities for Large Enrollment Undergraduate Programs (SCALE-UP) project, a peer reviewed chapter of Research-Based Reform of University Physics, (Redish, E., and Cooney, P., eds.), College Park, MD: Am Assoc of Physics Teachers.

43. Zavala, G., Alarcón, H., Domínguez, A. y Rodríguez, R. (2010). Sala ACE: Aprendizaje al servicio de la Educación. Revista Ciencia Conocimiento Tecnología. Pp. 36-40. Gobierno de Nuevo León.

44. Zavala, G., Domínguez, A. y Rodríguez, R. (2013, in press). ACE: Innovative Educational Model to Teach Physics and Mathematics for Engineering Students. ASEE 2013 Conference Proceedings.

45. Maab, K. (2006). What are modeling competencies?. ZDM, 38 (2). pp. 113-142.

46. Henning, H. y Keune, M. (2007). Levels of modelling competencies. En Blum, W., Galbraith, P. L., Henn, H.-W. y Niss, M. (Eds.), Modeling and Applications in Mathematics Education. The 14th ICMI Study, 225232. New York: International Commission on Mathematical Instruction ICMI.

47. Beneitone, P., Esquetini, C., González, J., Maletá, M., Siufi, G., \& Wagenaar, R. (2007). Reflexiones y perspectivas de la Educación Superior en América Latina, Informe Final Proyecto Tuning América Latina 2004-2007. Madrid, España: Universidad de Deusto.

48. Accreditation Board for Engineering and Technology [ABET]. (2011). Criteria for Accrediting Engineering Technology Programs. Retrieved from

http://www.abet.org/uploadedFiles/Accreditation/Accreditation_Process/Accreditation_Documents/Current tac-criteria-2012-2013.pdf

49. Organization for Economic Cooperation and Development [OCDE]. Informe PISA 2003. (OCDE, Ed.).

Learning (1st ed., p. 480). OCDE Publishing.

50. Rodríguez, R. (2010). El desarrollo de competencias de modelación en clase de matemáticas: un enfoque teórico. XXIII Reunión Latinoamericana de Matemática Educativa (RELME XXIII). CLAME: Guatemala, Guatemala.

51. Quiroz, S., Rendón, D. y Rodríguez, R. (2011). Las competencias de modelación matemática con apoyo en Webquest. Memorias de la XIV Escuela de Invierno de Matemática Educativa (p. 515).

52. Maple. http://www.maplesoft.com/products/maple/

53. Mathematica: http://www.wolfram.com/mathematica/

54. Wolfram Alpha. http://www.wolframalpha.com/

55. Texas Instruments: http://education.ti.com/calculators/products/LATINOAMERICA/home/

56. PhET. www.phet.com

57. Brook Cole/Cengage. Simulador del libro de Denis Zill. Ecuaciones Diferenciales. 